\title{
A complex case of fatal calciphylaxis in a female patient with hyperparathyroidism secondary to end stage renal disease of graft and coexistence of haemolytic uremic syndrome
}

\author{
Attilio Ignazio Lo Monte a,b,d, Maurizio Bellaviaa , Giuseppe Damiano d , Maria Concetta Giovialed, Carolina Maione ${ }^{\mathrm{d}}$, \\ Vincenzo Davide Palumbo ${ }^{\mathrm{a}, \mathrm{b}, \mathrm{d}}$, Gabriele Spinelli ${ }^{\mathrm{a}}$, Claudio Tripodo $0^{\mathrm{b}, \mathrm{c}, \mathrm{d}}$, Francesco Cacciabaudo da, ${ }^{\mathrm{a}, \mathrm{b}}$, Antonino Sammartano $0^{\mathrm{a}, \mathrm{b}}$, \\ Salvatore Buscemif , Salvatore De Luca ${ }^{a}$, Simona Di Gancia , Giuseppe Buscemi ${ }^{\mathrm{a}, \mathrm{b}, \mathrm{d}, \mathrm{e}}$
}

\begin{abstract}
Background. Calciphylaxis is a potentially fatal complication of persistent secondary hyperparathyroidism; its cause is still not clear. Unfortunately there is no close relation in severity of clinical picture, serological and pathological alteration. For this reason the prognosis is difficult to establish. Administration of sodium thiosulphate may reduce the precipitation of calcium crystals and improve the general clinical conditions before surgical parathyroidectomy, which seems the only therapeutic approach able to reduce the mortality risk in these patients.

Methods and Results. A 60 year old female patient suffering from End Renal Stage Disease, on haemodialysis from 2001 due to the onset of haemolytic uremic syndrome, underwent a kidney transplant in April 2008. After transplantation there was a recurrence of the haemolytic uremic syndrome, with temporary worsening of the graft. Six months later there was a definite loss of graft and return to dialysis treatment. On April 2010 a severe systemic calciphylaxis related to secondary hyperparathyroidism was diagnosed.

The patient underwent parathyroidectomy but, because of the unimproved clinical picture, treatment with sodium thiosulphate was initiated. There was only improvement in cutaneous lesions. The worsening general clinical condition of the patient caused death due to general septic complications.

Conclusions. The coexistence of haemolytic uremic syndrome and secondary hyperpathyroidism makes the prognosis poor and, in this case, therapy, which counteracts calcium crystals precipitation, has no effect. Preventive parathyroidectomy can be considered as the only possible treatment.
\end{abstract}

Key words: secondary hyperparathyroidism, calciphylaxis, kidney transplant, parathyroidectomy

Received: August 31, 2011; Accepted with revision: January 31, 2012; Available online: April 19, 2012

http://dx.doi.org/10.5507/bp.2012.018

${ }^{a}$ Department of Surgical and Oncological Sciences, Faculty of Medicine, University of Palermo, Italy

${ }^{b}$ PhD Research in Surgical Biotechnology and Regenerative Medicine, Faculty of Medicine, University of Palermo

'Department of Human Pathology, Faculty of Medicine, University of Palermo

${ }^{d}$ P. Giaccone University Hospital, Palermo

${ }^{e}$ Consorzio Interuniversitario dei Trapianti d'Organo, Rome

${ }^{f}$ Department of Surgical and Anaesthetic Sciences, University of Bologna

Corresponding author: Attilio Ignazio Lo Monte, e-mail: attilioignazio.lomonte@unipa.it

\section{INTRODUCTION}

Calciphylaxis is an extreme and potentially fatal complication of secondary hyperparathyroidism (SHPT) whose incidence is assessed between 1 to $4 \%$ of patients suffering from End Stage Renal Disease (ESRD). It is characterized by calcification of tunica media of skin arteries, subcutaneous fat tissues, visceral organs and muscles. These histological features are associated to a clinical picture characterized by cutaneous and subcutaneous manifestations and by the presence of violaceous nodular lesions of the skin that can evolve into tissue necrosis, ulcers that do not heal, and cutaneous gangrene (Fig. 1). In advanced stage these lesions may be found in internal organs such as heart and lung ${ }^{1}$ and consequent clinical symptoms.
The death rate for calciphylaxis is about $60-80 \%$ and depends not exclusively on organ involved in the pathological process but also on the extension of necrotic cutaneous lesions, possible sites of bacterial contamination that can lead to sepsis.

The extreme variability of symptoms is not clear yet and it does not seem related to serum parathormone (PTH) levels. It is probably due to calcium-phosphate ratio and individual variables not fully understood such as sensitization to PTH receptor, vitamin D levels and hypocalcaemia. For the above reasons, it is often very difficult to formulate a defined prognosis. Possible therapies that can modify the course of the disease are surgical parathyroidectomy ${ }^{2-4}$ which should be performed as soon as possible in order to restore physiological PTH levels- the administration of drugs for normalizing calcium-phospho- 

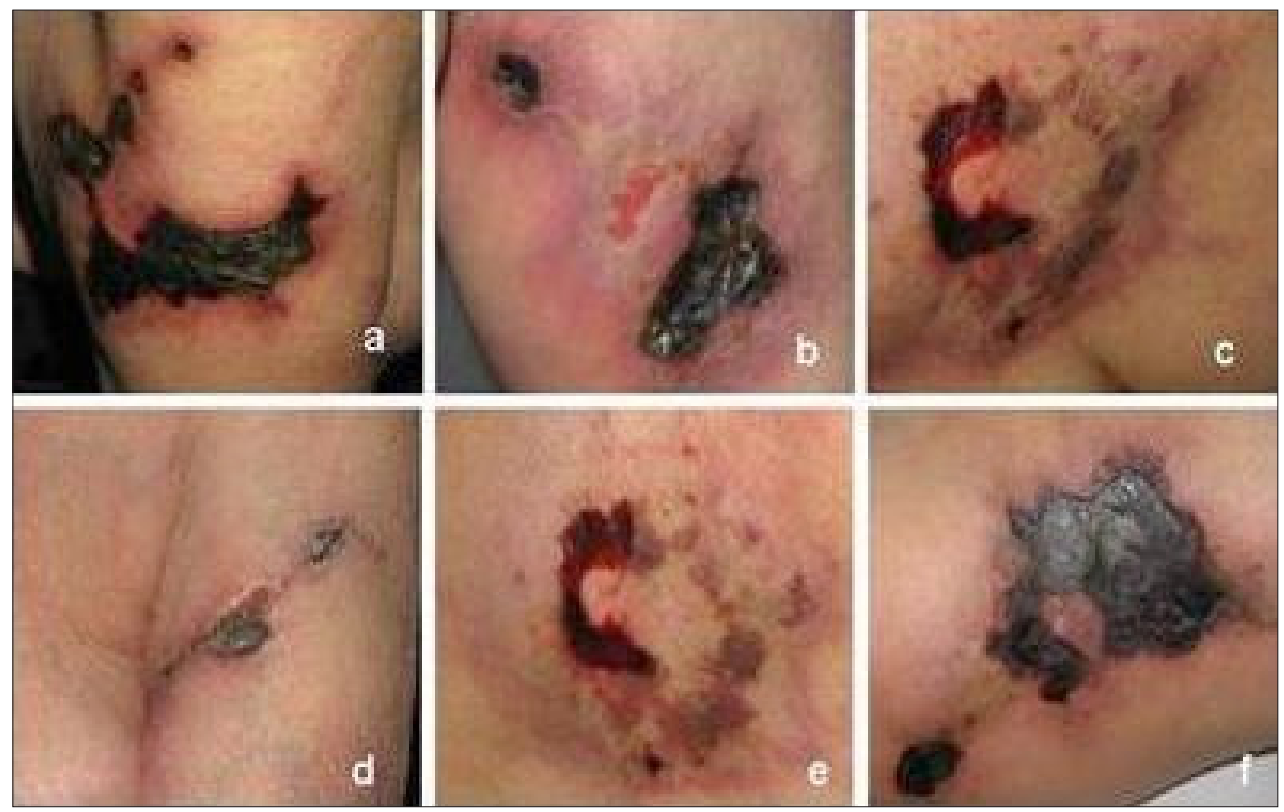

Fig. 1. Extensive ischemic tissue necrosis in a 60-yearsold woman showing bilateral proximal arms, thighs and buttock necrotic skin lesions $(a, b, c, d, e, f)$.

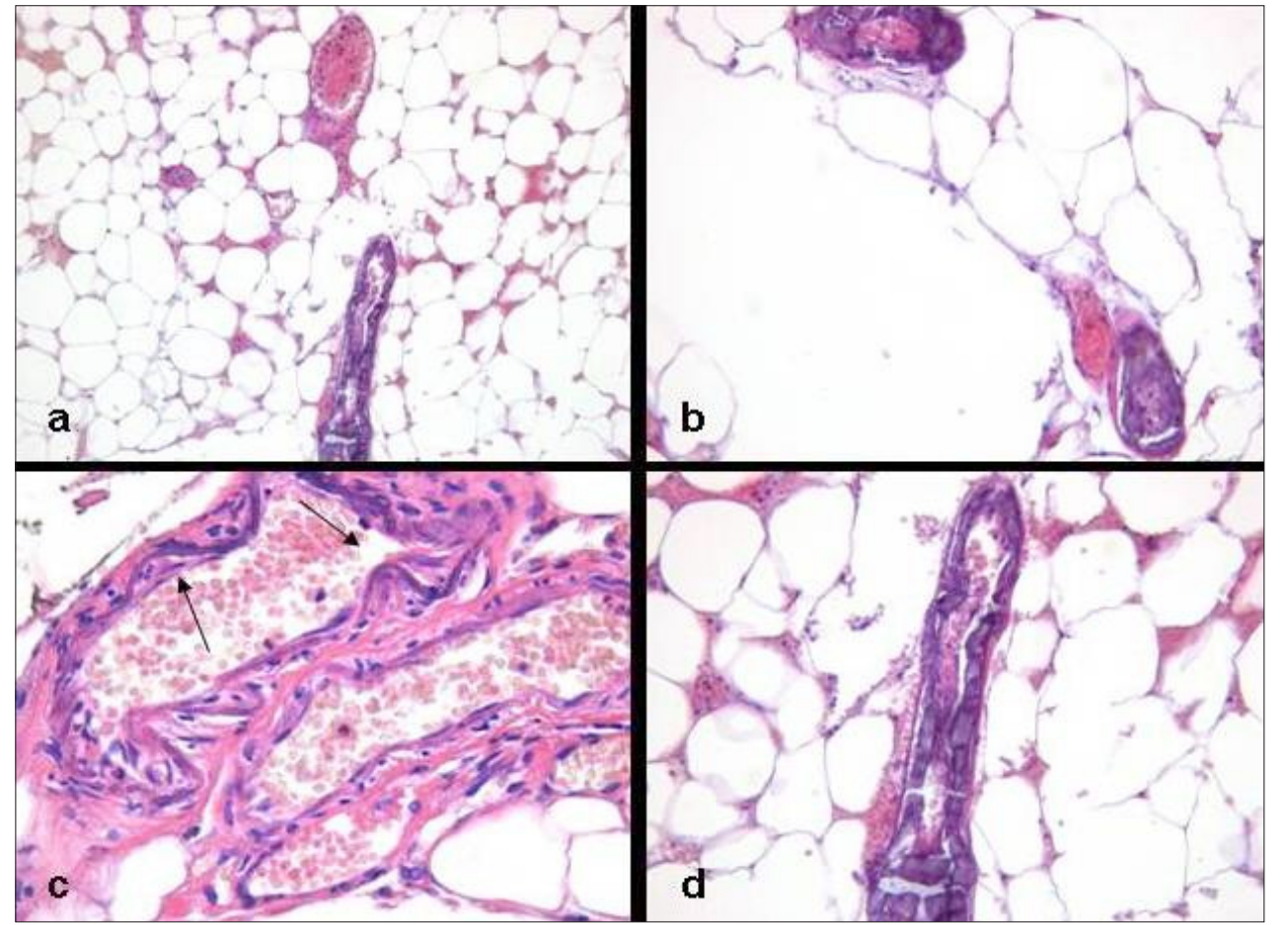

Fig. 2. Histopathological analysis of skin lesions showed a diffuse vascular calcification involving small vessels in the context of subcutaneous adipose tissue $(\mathrm{a}, \mathrm{b})$. Calcification mainly occurred in the intima (c) and media (d) of the small vessels and was associated with a variable degree of endothelial proliferation (arrows). (Haematoxylin and eosin, original magnifications: a, 200x; b-d 400x). rus balance, as sevelamer (a phosphorus binding drug) and Cinacalcet (that acts as a calcimimetic activating the calcium-sensing receptors thus reducing PTH secretion ${ }^{5}$ ), and technical stratagems such as reducing calcium levels in dialysis buffers.

It is reported that intravenous administration of sodium thiosulfate ${ }^{6,7}$ before surgical parathyroidectomy increases the solubility of calcium deposits, reduces disseminated precipitation of calcium crystals and counteracts occlusions in small and medium calibre arteries, improving clinical picture acting as antioxidant and calcium binding drug.

\section{CASE REPORT}

We report the case of a 60 year old female patient suffering from ERSD, on haemodialysis treatment from 2001 subsequent to haemolytic uremic syndrome (HUS), and who underwent a kidney transplant from a deceased donor on April 2008. Shortly after renal transplant, the relapse of HUS (accompanying with worsening of the graft) required plasma-aphaeresis, blood transfusions, and haemodialysis. The problem was resolved and graft function was resumed up to December 2008 followed by loss of the graft when the patient was returned to dialysis treatment. On April 2010 the patient came to our attention again for the onset of a severe clinical picture of skin lesions, 

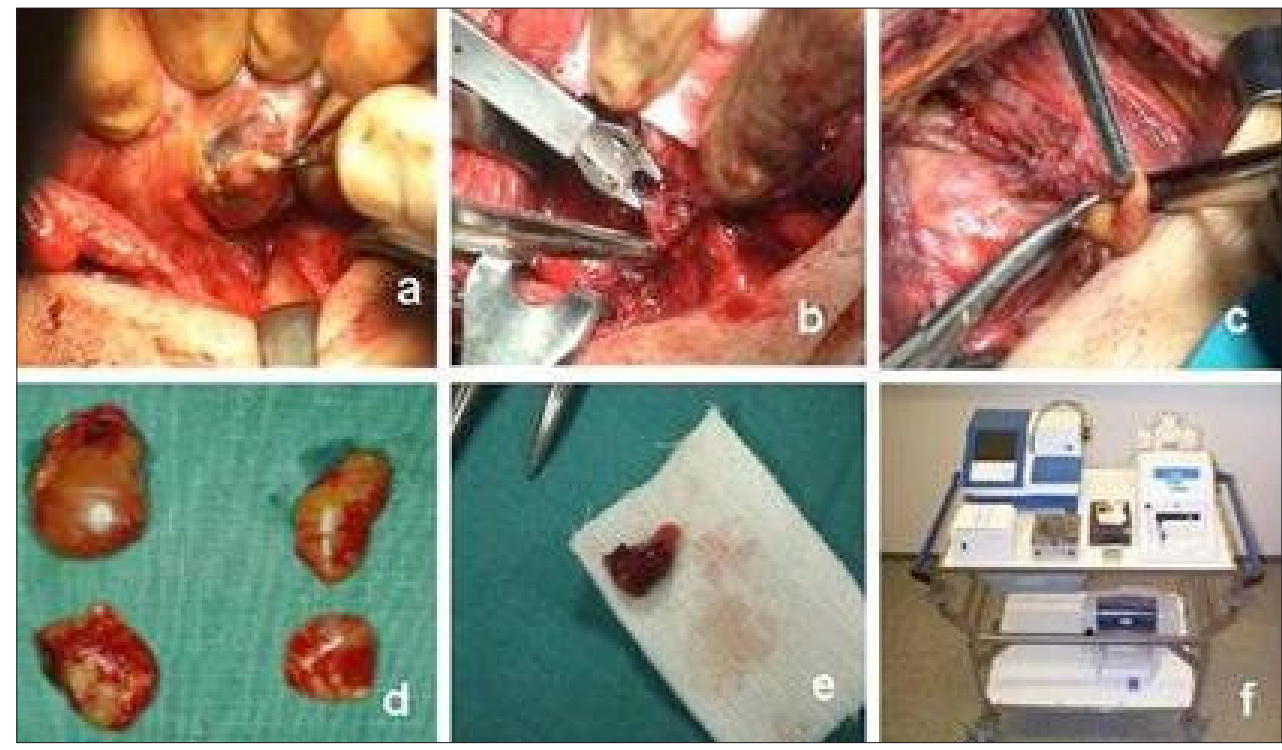

Fig. 3. Total parathyroidectomy: a) Identification, b) Dissection, c) Exeresis of parathyroid glands, d) Four parathyroid glands, e) Supernumerary gland, f) Chemiluminescent immunometric instrument for rapid PTH analysis (Future Diagnostic STAT-IO-I- PTH, US).

diffuse on trunk and extremities, and pain matching the systemic calciphylaxis due probably to the presence of an elevated PTH levels ${ }^{8}$.

During hospitalisation a cutaneous biopsy of the skin lesions was performed showing deposits of calcium and vascular lesions compatible with calciphylaxis (Fig. 2). For this reason we started a diagnostic workup monitoring calcium-phosphate metabolism and performing a parathyroid ultrasonography and technetium-99m-sestamibi scintigraphy that confirmed SHPT, with a PTH level of $1025 \mathrm{pg} / \mathrm{ml}$ (normal range 10-65 pg/ml).

Parathyroidectomy (Fig. 3), performed using a intraoperative dosage of PTH (Future Diagnostic STAT-IO-IPTH Kit, US), removed the glands leading to a reduction of PTH levels of more than $88 \%$, Table 1 shows the main clinical data regarding bone metabolism before and after intervention. Histological analysis confirmed that all the five glands removed showed signs of hyperplasia ${ }^{9,10}$. Unfortunately, after surgical intervention, the clinical picture did not improve thus it was decided to initiate therapy based on sodium thiosulphate at dosage of 25 grams three times a week after dialysis treatment.

The treatment with sodium thiosulphate improved the skin lesions but was ineffective in terms of the general clinical status, which, instead, worsened because of the appearance of septic complications that, although treated with aggressive broad-spectrum antibiotics, caused the death of the patient.

\section{DISCUSSION}

HUS and SHPT have both small and medium calibre arteries as targets: their coexistence is considered a negative prognostic factor particularly when the SHPT is associated to myelofibrosis ${ }^{11}$. The role of metastatic calcium deposits in vessels, causing a complex hypersensibility reaction, plays probably the main role in progression of the disease particularly when associated with the onset of
Table 1. Clinical data regarding bone metabolism before and after parathyroidectomy (PTx).

\begin{tabular}{lcc}
\hline Bone metabolism data & Before PTx & After PTx \\
\hline PTH & $1025 \mathrm{pg} / \mathrm{ml}$ & $4.05 \mathrm{pg} / \mathrm{ml}$ \\
Total Calcium & $9.1 \mathrm{mg} / \mathrm{dl}$ & $9.6 \mathrm{mg} / \mathrm{dl}$ \\
Phosphorus & $5.2 \mathrm{mg} / \mathrm{dl}$ & $1.5 \mathrm{mg} / \mathrm{dl}$ \\
Alkaline Phosphatase & $108 \mathrm{U} / 1$ & $404 \mathrm{U} / 1$ \\
\hline
\end{tabular}

a thrombotic micro-angiopathy related to HUS. In such a clinical picture the administration of sodium thiosulphate pic precipitation of calcium crystals.

\section{CONCLUSIONS}

Calciphylaxis has a high mortality rate. Its pathogenesis is still not clear because only few patients suffering from SHPT develop such a complication and, further, there is no correlation between clinical picture and lab tests such as those evaluating calcium-phosphate ratio. Probably a main role is played by underestimated preexisting vascular alterations that lead to calcium deposits. Published data show that the presence of supernumerary glands is associated to pathologies causing thrombotic lesions; in the light of the above considerations, we believe that HUS should be considered a negative prognostic factor. Moreover, the appearance of skin lesions on the proximal side of the upper and lower limbs is related to a higher mortality rate ${ }^{12}$.

We conclude that, in absence of tools for risk stratification for these patients, the therapy of choice is a advanced lesions. is insufficient to counteract the deleterious effect of ectopreventive parathyroidectomy before the appearance of 


\section{ACKNOWLEDGEMENT}

We thank Consorzio Inter Universitario dei Trapianti d'Organo for funding the purchase of the instrument used to monitor intraoperative parathormone.

\section{REFERENCES}

1. Suryadevara M, Schurman SJ, Landas SK, Philip A, Gerlach CB, Tavares T, Souid AK. Systemic calciphylaxis. Pediatr Blood Cancer 2008:51:548-50.

2. Coates T, Kirkaland GS, Dymock RB, Murphy BF, Brealey JK, Mathew TH, Disney APS. Cutaneous necrosis from calcific uremic arteriolopathy. American Journal of Kidney Diseases 1998;32:384-91.

3. Wenzel-Seifert K, Harwing S, Keller F. Fulminant calcinosis in two patients after kidney transplantation. Am J Nephrol 1991;11:497500.

4. Fox R, Banowsky LH, Cruz AR. Post transplant calciphylaxis: successful with parathyeoidectomy. J Urol 1983;129:362-3.

5. Prey S, Sparsa A, Durox H, Allot V, Pommepuy I, Salem A, Roux C, Labrousse F, Bonnetblanc JM. Calciphylaxis trated by cinecalcet: a medical alternative to parathyroidectomy. La Revue de medicine interne 2008.
6. Tindni A, Gaurav K, Panda M. Non-healing painful ulcers in a patient with chronic kidney disease and role of sodium thiosulfate: a case report. Cases Journal 2008;1:178.

7. Subramaniam K, Wllance H, Sinniah R, Saker B. Complete resolution of recurrent calciphylaxis with long-term intravenous sodium thiosulfate. American Journal of Dermatology 2008;49:30-4.

8. Landau D, Krymko H, Shalev H, Agronovich S. Transient severe metastatic calcification in acute renal failure. Pediatr Nephrol 2007;22:607-11.

9. Gioviale MC, Gambino G, Maione C, Luna E, Calderone F, Di Bona A, Buscemi G, Romano M, Lo Monte Al. Intraoperative parathyroid hormone monitoring during parathyroidectomy for hyperparathyroidism in waiting list and kidney transplant patients. Transplantation Proceedings 2006;38:1003-5.

10. Gioviale MC, Gambino G, Maione C, Romano G, Damiano G, Cocchiara G, Pirrotta C, Moscato F, Lo Monte Al, Buscemi G, Romano M. Use of monitoring intraoperative parathyroid hormone during parathyroidectomy in patients on waiting list for renal transplantation. Transplantation Proceedings 2007;39:1775-8.

11. Bellavia M, Gioviale MC, Damiano G, Palumbo VD, Cacciabaudo F, Altomare R, Buscemi G, Lo Monte Al. Is secondary hyperparathyroidism-related myelofibrosis a negative prognostic factor for kidney transplant outcome? Medical Hypotheses 2011;77:557-9.

12. Angelis $M$, Wong LL, Myers SA, Wong LM. Calciphylaxis in patients on hemodialysis: a prevalence study. Surgery 1997;122:1083-90. 